\title{
UNA CONVERSACIÓN CON ISABEL ALLENDE
}

\author{
POR \\ Pilar Álvarez-Rubio \\ University of California, Berkeley
}

Clara del Valle, la indomable abuela de La casa de los espiritus (1982), sugiere a su nieta agonizante que la escritura la ayudará a sobrevivir el suplicio al que está siendo sometida por sus torturadores. En otro de los innumerables casos en que la vida imita al arte, la escritora chilena Isabel Allende, como su personaje, logra sobrevivir momentos de profundo dolor con su propia escritura. Hoy, el escribir es un paliativo para la reciente pérdida de su hija, como al principio de su carrera novelística lo fue para la sobrevivencia en el exilio.

La selección que sigue es parte de una conversación con Isabel Allende que se llevó a cabo en Corte Madera, California, el 28 de enero de 1993, después de haber sido postergada en dos ocasiones por momentos de mayor trascendencia: la muerte de mi compañero de muchos años en la primera ocasión y la muerte de la hija de Isabel, en la segunda. Estas circunstancias impartieron a nuestra conversación un tono personal que esfumó mi inicial aprensión de entrevistar a un personaje de la notoriedad de Allende: una eximia periodista, la novelista más publicada de América Latina y la sobrina del difunto presidente Salvador Allende. La significancia primordial de esos momentos eliminó las barreras fútiles que separan a los seres humanos, y entonces, Isabel Allende ya no fue sólo la novelista de renombre internacional, sino que ante todo la mujer, la madre, la compatriota. El personaje público se transformó en uno privado y la conversación fluyó naturalmente, a veces llegando a confidencias mutuas que quedaron fuera de impresión, otras a agradables momentos de hilaridad, y siempre siguiendo la línea central de su trabajo literario.

Álvarez: Debido a las circunstancias en que el proceso de esta entrevista se ha llevado a cabo no puedo evitar preguntarte sobre el tema de la ausencia, la pérdida, y sobre el tema de lo materno que parecen regir en tus primeras novelas.

Allende: Debe ser porque en mi vida la relación más antigua, poderosa y fuerte, el amor más grande de mi vida ha sido mi madre. Mi mamá me distinguió entre sus hijos con un amor incondicional, que me sirvió como plataforma de despegue para todo lo que he hecho en mi vida y para tener una especie de audacia, porque en cualquier lío en que me meta, siempre puedo volver donde mi mamá. No lo he hecho, pero tengo esa sensación maravillosa de que ella es mi último refugio. Pienso que si mi madre me quiere, el resto de la humanidad me quiere también. Yo quiero a mis hijos en la forma en que mi mamá me quiso a mí; quiero a los hombres que he tenido en la vida con una intensidad similar a la del amor de mi madre. 
Álvarez: ¿No has sentido la ausencia de la figura paternal?

Allende: Pensé yo que no, pero ahora con la muerte de mi hija y con todo lo que me ha pasado recientemente me doy cuenta que cargo a la espalda muchas pérdidas y abandonos, muchas separaciones; desde la primera separación que es la de mi padre, hasta el hecho de que mi madre se casó con un diplomático y viajábamos siempre. De niña pasaba despidiéndome de colegios, amigos, lugares, paisajes, climas. Y ese eterno decir adiós se fue sumando. Cuando me tocó enfrentar la última y más grave separación de mi vida, que fue la muerte de mi hija Paula, me invadió una sensación de abandono, de soledad, me volvió todo lo del exilio, la pérdida de Chile, la pérdida de la familia, de las raíces. Es duro, pero creo que es bueno, desde el punto de vista del alma primero, y tal vez de la escritura después.

Álvarez: He notado en en toda tu escritura un fuerte componente autobiográfico. Pensaba por ejemplo en tu última novela, El plan infinito, dedicada a tu esposo y con un final donde se puede identificar un encuentro casi directo entre Isabel Allende y William Gordon, no entre el autor y el personaje como en Niebla, por ejemplo.

Allende: Sí, pero ese libro es ficción y Gregory Reeves no es Willie. Aunque hay muchas cosas de su vida y muchas cosas de su personalidad, me robé vidas ajenas.

Álvarez: Pero ¿cuán importante es lo autobiográfico o la relación de la realidad en tu ficción? ¿Sacas mucho de ahí?

Allende: No tengo una gran imaginación; lo que yo tengo es una especie de capacidad para tomar cosas de la realidad y transformarlas, pero casi todo lo que escribo tiene una base real; no tanto de las biografias de otras personas como de acontecimientos. Por ejemplo, leo que en Los Angeles los adolescentes corren contra el tren para desafiarse unos a otros, y muchos mueren. Se me ocurre que un hijo mío podría estar ahí, y me meto en esa historia y empiezo a darle vueltas. Y de repente me doy cuenta que me sirve para la novela que estoy escribiendo. Otras veces hay algo que me impacta y no lo uso de inmediato, sino que tomo nota y lo guardo. Tengo una carpeta donde voy poniendo recortes de prensa y después de un tiempo miro y descubro joyas, verdaderas gemas.

Álvarez: Entonces ¿ése es tu método para escribir?

Allende: También entrevisto gente cuando necesito algo específico. En El plan infinito necesitaba un veterano de Vietnam. Apareció en mi vida en el momento preciso la persona adecuada. Nos encerramos por horas, por días, con una grabadora y así salió el capítulo sobre la guerra. El personaje de Carmen lo hice con dos personas de la vida real y también con elementos de ficción.

Álvarez: Me pareció interesante el personaje de Carmen Morales. ¿Se te ocurre alguna vez retomar las vidas de estos personajes y continuarlas en otras novelas, como hacía Galdós, por ejemplo?

Allende: No lo creo. Un libro nunca se termina; hay un momento en que te das por vencida, ya no puedes más, estás saturada con los personajes y con la historia. Y supongo que ése es el momento de terminarlo, porque siempre podrías corregirlo y agregarle más. Una historia nunca se termina, la vida sigue, pero el autor se cansa de contar. Cuando cierro el libro con la última página no vuelvo a leerlo y no vuelvo a pensar en él más; se me va de la cabeza ... 
Álvarez: De todas maneras tienes que releer para corregir ....

Allende: Casi no corrijo las galeras, porque el manuscrito final que entrego ha sido sobrecorregido. Puedo pasar dos años corrigiendo el original.

Álvarez: A propósito de correcciones, he oído que tu mamá es una de tus críticas literarias.

Allende: Mi mamá es mi crítica más fuerte, la única a quien le aguanto que me diga las cosas horribles que me dice [risas]. Cuando termino un libro se lo mando a Chile y ella se toma un avión, se viene con un lápiz rojo y nos encerramos en el comedor a pelear. Cuando se va, de las 600 páginas que tenía el libro me quedan como 15 más o menos que no están rayadas [más risas]. Ella es mi crítico más feroz. Lee todo lo mío con una paciencia, una prudencia, y una meticulosidad increíbles. Después yo rehago el libro, y ya no se lo muestro más a mi mamá ni a nadie. De ahí sale directo a las máquinas. No tengo editores ni nadie que corrija ni opine sobre lo que escribo, solamente mi madre.

Álvarez: Otra vez esa conexión tan fuerte con lo materno ... No solamente entre tú y tu madre, sino que también con tus hijos ....

Allende: ¡Y con los nietos! La tengo fuertísima con los nietos. Con mis nietos la relación es de enamoramiento. Cuando una está enamorada (yo estoy enamorada de mi marido, por eso te digo) y no te llaman por teléfono, te duele una cosa aquí en el estómago, crees que te vas a morir, que si no lo ves un día, la inquietud es tan grande que no puedes descansar, te pica el cuerpo ... eso mismo me pasa con los nietos [carcajadas]. Si no los veo un día siento una ansiedad igual que ante el amante ausente. ¡Totalmente enamorada de los chiquillos!

Álvarez: ¿Tienes algún proyecto de escritura en mente?

Allende: Sí, pero no puedo hablar de eso.

Álvarez: ¿Otro día me das la exclusiva entonces?

Allende: No, nunca hablo de lo que estoy haciendo porque soy muy supersticiosa, pienso que si lo digo se esfuma. Las palabras se las lleva el viento y después ya no las puedo escribir. Necesito guardar toda mi energía para escribir.

Álvarez: ¿Cuándo terminaste de escribir El plan infinito?

Allende: En octubre del año 91.

Álvarez: Y ya empezaste algo más ...

Allende: Debería haber empezado el 92 pero se enfermó mi hija y no hice nada, pasé todo el año con eila. Ahora acabo de empezar otro libro pero no sé qué va a ser todavía.

Álvarez: Volvamos a la relación ficción/realidad, que es un tema que se ha debatido bastante en las letras latinoamericanas. El crítico Fredric Jameson estima que en general la ficción de los llamados países del tercer mundo son alegorías de su situación sociocultural e histórica, al contrario de lo que sucedería con la ficción del primer mundo que se puede dar el lujo de jugar con la forma, la fantasía y el arte. Basándose en esta idea algunos críticos acusan a la literatura latinoamericana de carecer de independencia artística. ¿Qué opinas al respecto?

Allende: Bueno, si independencia significa alejarse de la realidad y meterse en una torre de marfil que generalmente está protegida por el gran paraguas de las universidades y las fundaciones, y si eso significa también escribir para los críticos y para que te estudien, no estoy interesada. Prefiero mil veces quedarme con mi literatura "subdesarrollada" que 
coge al lector por el cuello y lo hace pensar y sentir una realidad que tal vez en ese momento no es la suya, pero podría serlo.

Álvarez: ¿Crees tú que el escritor latinoamericano tiene la responsabilidad de reflexionar sobre la realidad que lo circunda?

Allende: No siento la literatura como responsabilidad. Cuando empecé a escribir y cuando era mucho más joven sentía que todo escritor latinoamericano tenía un deber frente a la realidad que se vive en nuestro continente. Además eran los peores años de las dictaduras. Sin embargo, ahora soy menos pretenciosa, me doy cuenta que los escritores no tenemos respuestas. A menudo ni siquiera sabemos denunciar las cosas; sólo somos testigos de los eventos. De mentira en mentira vamos descubriendo partículas de verdad. Ése es nuestro oficio: hacer las preguntas que se hace todo el mundo. No tenemos respuesta; por lo menos yo no conozco a nadie que la tenga.

Álvarez: Sin embargo en Latinoamérica tradicionalmente el escritor se ha adjudicado el papel de intérprete de la realidad ...

Allende: Yo creo que todos los artistas en América Latina se sienten muy comprometidos con la realidad. Tú y yo venimos de Chile, donde de lo único que se habla es de política y de comida ... de nada más. Y en muchas partes es así. Es tan fuerte la realidad, hay tantos contrastes, tanta violencia, tantas cosas que es importante cuestionar; las preguntas son inevitables en la escritura y en la vida misma.

Álvarez: Para escribir sobre la realidad chilena tienes tu vivencia personal como materia prima. Para representar a una familia chicana, o la cultura de los sesenta en Berkeley en El plan infinito ¿cuál ha sido tu procedimiento creativo?

Allende: Cuando llegué a este país me sentí muy marginal y muy extranjera, no conocía las reglas, hablaba mal el idioma, no podía ir ni al cine porque no entendía lo que hablaban los actores. Me sentí muy aislada y luego me di cuenta que había millones de latinos en la misma situación y que existía una especie de subcultura, o cultura paralela, que era la nuestra, a la cual yo no me había integrado. Me fascinó esa relación amor/odio que ha habido entre latinos y anglosajones durante doscientos años en esta parte del mundo; es una historia de codicia, de violencia, de lujuria y de esperanza que tiene como fin inevitable la integración. Porque no hay duda, eso va a pasar de todas maneras, tarde o temprano. Y a pesar de los alambres de púa y a pesar de los perros de la policía, se cruzan miles de personas para allá y para acá de la frontera todos los días. Es un fenómeno extraordinariamente rico en matices e interesante para un escritor. Me plante escribir sobre California y sobre el choque entre el mundo latino y el norteamericano. Esto surgió en un chispazo el día que me casé, mira que es curioso. Me casé con Willie e hicimos una pequeña ceremonia privada para los amigos. Nos casó un señor que tenía un certificado de esos del Universal Church donde por $\$ 25$ tú te conviertes en casamentero. Mi marido, siendo abogado, no pudo conseguir ningún juez que nos casara. Bueno, Willie y yo nos vemos tan distintos que somos como de otra especie. Willie es un hombre blanco alto, de ojos tan claros que parecen transparentes ... al lado mío es como tener un San Bernardo con Chihuaha juntos. Ese señor adorable que nos casó dijo: "Ustedes dos se han juntado para servir de puente entre dos culturas". Para mí fue como un chispazo comprender que ésa es una linda misión. Willie habla castellano perfectamente, ha vivido entre latinos; toda su vida ha estado tendiendo ese puente. Yo traigo algo de nuestra cultura a esta parte 
del mundo. Tengo el privilegio, por encima de otras personas que vienen como yo, latinos emigrantes también, de tener quién quiera publicar y quién quiera leer mis libros. Eso me permite hablar por los que no tienen voz, por los que no han podido ser escuchados. Escribir un libro sobre eso era un proyecto fascinante, pero no sabía cómo hacerlo. Un día que Willie contó su experiencia de niño blanco en el ghetto latino de Los Angeles y entonces pensé que sería una historia sumamente original. En vez de contarlo desde el punto de vista del latino emigrante, invertí la situación. Y así cambia completamente la perspectiva. Me costó mucho más escribir la parte americana que la parte latina. Hice muchas entrevistas, fui a Los Angeles a hablar con la gente, recorrí casi todos los lugares mencionados en el libro, menos Vietnam. Me sirvió mucho la experiencia de Willie en el ghetto cuando era niño; también me ayudaron familias que él conoció en aquella época y me sirvieron de modelo para la familia Morales. Había mucho material. Me costó mucho más la parte americana, pero no porque fuera difícil encontrar la información, sino porque para mí es difícil escribir de eso desde adentro.

Álvarez: ¿Entonces te sientes cómoda dentro de la cultura chicana?

Allende: Sí, me siento cómoda con los latinos en esta parte del mundo. No sé si sería igual en Florida. Pero aquí me siento muy cómoda.

Álvarez: En los Estados Unidos pareciera que en general, el interés por la literatura latinoamericana estuviera concentrado en el ambiente académico. Porque a nivel masivo la aceptación está todavía restringida a autores como García Márquez, Puig, y Allende. ¿Cómo te explicas esto en general, y específicamente en tu caso?

Allende: A la gente en este país no le gusta leer traducción. Lo mismo es aplicable a la literatura francesa, a la literatura alemana, a la literatura escandinava. La gente no lee traducción y a los editores no les gusta publicar traducción si pueden evitarlo. Ésa es una razón. Sin embargo, lo latinoamericano está entrando en Inglaterra y los Estados Unidos recientemente. Cuando hubo la gran emigración de latinoamericanos, durante la década de dictaduras del 73 al 83 más o menos, muy pocos vinieron a los Estados Unidos o fueron a Inglaterra; en cambio, muchos llegaron a Alemania, Francia y a los países escandinavos. Esos países son más permeables a nuestra cultura. Ahora empiezan a conocerse más y más los escritores, la música, la comida latinoamericanos. Siempre se empieza por la comida, ¿te has fijado?. La comida, la música y después otras expresiones del arte.

Álvarez: Sí, me acuerdo de La Peña en Berkeley, que con empanadas y vino tinto abrió un foro cultural después del golpe militar del 73 en Chile.

A propósito de la aceptación universal de tu obra, he leído que La casa de los espiritus se está filmando en Europa. ¿Has participado en la realización de este proyecto?

Allende: Sí, ya empezó la filmación. El director es Billie August, el danés que hizo Pele el conquistador y Best Intentions; dicen que es el sucesor de Ingmar Bergman. Billie ha logrado reunir una cantidad increíble de artistas. Esta película va a costar 30 millones de dólares. El elenco está compuesto por Meryl Streep, Glenn Close, Jeremy Irons, Wynona Ryder, Vanessa Redgrave, Antonio Banderas y otros de alto nivel. Con semejante elenco ha habido mucha prensa, porque llama la antención que hayan podido reunir a tantas estrellas. El otro día me llamaron de Chile de una radio para preguntarme cómo me sentía yo de que una obra chilena tuviera esta repercusión, y yo le dije bueno, no es porque la obra sea chilena ni porque sea mía. Yo no siento en absoluto que el crédito sea mío, siento 
que el crédito es completo de Billie August y que si él hubiera escogido otro libro habría hecho una cosa igual de espectacular. Esta película será sólo mérito suyo.

Álvarez: Tú, como creadora de esta historia, ¿te sientes cómoda en darle carta blanca para hacer esta transposición cinematográfica?

Allende: Absolutamente. ¿No te digo que es otro producto? En este momento se está haciendo una obra de teatro en Inglaterra, que tampoco me pertenece. La casa de los espiritus salió de mis manos hace doce años atrás y ya no es mía. Tal vez nunca fue mía. Yo creo que el escritor pone como la mitad y la otra mitad la pone el lector, por eso cada vez que un libro se lee, cambia. Cada lector de acuerdo a su biografía, a su experiencia, a su sentimientos, lo rehace.

Álvarez: ¿Como si el libro se volviera una entidad autónoma, entonces?

Allende: Claro. ¿Por qué hay gente que lo odia, otra que lo adora y otra a quienes les da lo mismo, si no es porque cada uno no le pone su propia carga?

Álvarez: ¿Cuál es tu actitud ante la página en blanco? ¿Planificas mucho o lo haces espontáneamente? Por ejemplo, hay un crítico que dice que Eva Luna es una novela picaresca, otro dice que es un Bildungsroman. Cuando empezaste la novela, ¿te lo propusiste en estos términos?

Allende: Nada. No me propongo nada. Escribo por el placer infinito de la escritura. Prendo mi computadora y escribo la primera frase con el corazón abierto. Los personajes y yo vamos a crear algo que ni siquiera sé para dónde va. A menudo tengo un plan pero no soy capaz de seguirlo, porque los personajes se apoderan de la historia. Me pasó con Eva Luna. Había creado desde el principio esas dos vidas paralelas que eran la de Huberto Naranjo y Eva Luna que lógicamente se juntarían en un momento para ser amantes o algo así. Cuando llegué a ese punto no resultó porque Huberto Naranjo se había convertido en un macho desagradable. Se había desarrollado así a pesar mío y no pude cambiarlo; él era más fuerte que yo. Finalmente tuve que traer un personaje de Austria, a Rolf Carlé, para meterlo en la historia. Rolf Carlé, que era un pretexto, empezó a crecer a crecer, a crecer y volvió a aparecer en los Cuentos de Eva Luna. Se convirtió en un personaje muy importante para mí.

Álvarez: Entonces podríamos generalizar y decir que eres una autora más espontánea que autoconsciente.

Allende: Así soy para todo en mi vida. También para cocinar [risas].

Álvarez: ¿Nunca sientes la escritura como un peso entonces?

Allende: No, es pura alegría. La vida suele ser un peso porque tiene momentos muy graves, con el karma muy pesado, pero el proceso de la escritura, aunque estés escribiendo la cosa más dolorosa, es siempre una orgía de los sentidos.

Álvarez: ¿Crees en el karma?

Allende: Creo que hay un destino, que puedes hacer mucho para modificarlo, pero creo que hay cosas con las que uno nace y que no se tiene control sobre ellas. ¿Por qué te toca nacer hombre o mujer, sano o enfermo, blanco o negro, en la China o en los Estados Unidos? No creo que sean coincidencias sino que corresponden a una especie de diseño misterioso. Ahora, con lo que pasó con mi hija, te puedo decir que uno controla muy poco. El libre albedrío es algo muy interior, de tu conciencia, no hay mucha libertad en cómo puedes hacer tu vida. 
Álvarez: Se advierte en toda tu obra un gran interés por los personajes marginales. ¿A qué se debe esa fascinación?

Allende: Porque son mucho mas entretenidos que la gente con sentido común [estruendosas risas compartidas].

Álvarez: De acuerdo. Ésa es una razón ....

Allende: Y después, porque yo creo que los escritores son casi siempre marginales. Yo por lo menos así me siento. Yo nunca realmente pertenecí a ninguna parte. No pertenecí en Chile en mi familia, no pertenecía en mi medio social; siempre fui como una desclasada, palabra que mi mamá detesta, pero es verdad. Nunca sentí que los valores de la clase social en que yo nací me calzaban para nada. Me sentí fuera de la Iglesia, fuera de la familia, fuera de la sociedad.

Álvarez: ¿Y cómo funcionabas entonces en esa sociedad?

Allende: Como una gran rebelde. Siempre con humor, me hacía perdonar la rebeldía, la agresividad y el ser diferente porque lo echaba a la risa. Nadie me tomaba realmente en serio. Por ejemplo, me casé con un hombre muy bueno y muy tolerante. Yo era la esposa más atípica que puedas imaginarte, pero como todo esto lo llevaba con humor, aparecía como que yo era muy original; pero no era realmente un problema. No era un peligro ni para el matrimonio, ni para la sociedad, ni para nadie, pero en el fondo todas esas cosas que decía con humor las sentía profundamente y las sigo sintiendo. Hablaba mucho contra el machismo. Toda mi vida he estado cuestionando la autoridad, toda forma de autoridad, empezando con la autoridad patriarcal. La autoridad de la Iglesia, la del gobierno, la de las jerarquías, de las clases sociales; todo lo he cuestionado siempre, desde niña. ¡Imagínate cuánta agresión he recibido!

Álvarez: Tu obra ha sido alabada porque en ella las mujeres rompen el silencio que se les ha impuesto por tiempos inmemoriales. Por otro lado, también se ha dicho que tus heroínas refuerzan estereotipos, y aquí hago una paráfrasis: la mujer y su afición a la magia y al espiritismo; el atributo "normal" de procrear; la pasividad de las campesinas violadas; Alba, ante la tragedia, aguanta y espera pero no participa activamente (excepto con escritura); otras son dolorosamente ingenuas, como Irene. ${ }^{1}$ ¿Qué dices ante este cuestionamieto de la posición ética de tu feminismo?

Allende: Creo que la mayor parte de mis personajes se parecen mucho a la vida real. $\mathrm{Y}$ no invento personajes para que sirvan de modelo a las feministas a ultranza ni a las muchachitas que quieren ser feministas, sino que simplemente cuento cómo es la vida. La vida está llena de personas contradictorias. Yo misma lo soy. He sido muy liberal, feminista y atrevida para hacer todas las cosas que a las mujeres de mi generación no les estaba permitido hacer; sin embargo me pinto los labios y ando con taco alto, y de lo que estoy más orgullosa es de la maternidad. Creo que soy una hija y una madre ejemplar, y me enorgullezco de eso tremendamente ¿Qué tiene que ver el feminismo con eso? $¡$ ¡ Absolutamente nada! Alba, Irene y otras protagonistas son mujeres un poco ingenuas que van despertando de a poco a la realidad. ¿Dime tú, a cuánta gente no le pasa eso? A

\footnotetext{
${ }^{1}$ Parafraseo las ideas presentadas por Gabriela Mora en su artículo: "Las novelas de Isabel Allende y el papel de la mujer como ciudadana", incluído en la revista Ideology and Literature (Spring 1987) 53-61.
} 
mí misma me pasó en Chile. No creas que nací con mis ideas políticas claras, decidida a hacer lo que me parecía correcto. ¡No! Estaba llena de dudas y de confusiones y me costó muchísimo darme cuenta de qué era lo que estaba sucediendo en Chile realmente. Y cuando me di cuenta, ya estaba metida hasta el cuello y tuve que irme del país. Pero sucedió de a poco, no fue que al día siguiente del golpe militar ya tenía mis ideas claras y estaba haciendo actos heroicos, no. En general la vida es así. Ahora, respecto a la campesina violada pasivamente, dime tú, ¿cuántas campesinas violadas se rebelan ante el hecho? Porque hay ahí una carga tremenda que no es sólo el hecho de ser violada, es toda una infraestructura social, política y económica que las mantiene en una posición humillante por generaciones, por siglos. ¿Y les vas a pedir tú que salgan heroicamente a defenderse? Tal vez haya una que lo haga, pero no es el personaje que te sirve para la novela. En la novela te sirve el que corresponde a la realidad. Por supuesto que hay militares buenos, muchos militares buenos, pero el que a mí me sirve para la novela no lo es. Yo necesito el torturador, que también es una realidad.

Álvarez: El feminismo en Chile es un movimiento de gran envergadura, con mucho apoyo social, en incluso con apoyo oficial. Hay un Ministerio de los Asuntos de la Mujer ¿Estás en contacto con las feministas chilenas?

Allende: Sí estoy en contacto siempre con Chile. Voy todos los años si puedo. Tengo muchas amigas periodistas y recibo información. Es curioso. Las mujeres en Chile siempre han sido fuertes y organizadas, bastante independientes en la vida privada y en la organización comunitaria, pero cuando se trata de tomar el poder, no sé por qué, dan un paso atrás y siempre éste queda en manos de los hombres. Los hombres son los que tienen el poder económico y el poder político y las mujeres no han tomado eso por asalto todavía en Chile, salvo excepciones por supuesto.

Álvarez: Hablábamos antes sobre los personajes marginales en tus novelas. El último es Gregory Reeves, que pasa parte de su vida en Berkeley, que también es un lugar marginal dentro de la sociedad norteamericana (los años sesenta; el "Día de los pueblos indígenas" en vez del "Aniversario del descubrimiento de América", etc.) ¿Qué me dices de tu experiencia docente en la Universidad de California-Berkeley? Berkeley, como espacio marginal, parece ser fascinante para ti, ¿no?

Allende: Fascinante. La parte de Berkeley está hecha con mucho cariño, se nota el gusto con que la escribí. Mi experiencia docente fue fantástica. Tuve un curso de "Creative Writing Long Narrative" y aprendí mucho, pero en ese tiempo no pude escribir ni una palabra de lo mío porque estaba metida con las quince novelas que estaban escribiendo mis estudiantes. Pasaba con las novelas dentro de la cabeza, dándoles vueltas y vueltas. Uno de ellos, una muchacha que trabajaba poco, pero que tenía un gran talento, va a publicar ahora su primera novela con bombo y platillo.

Álvarez: La casa de los espíritus y De amor y de sombra fueron escritas en el exilio y sobre la realidad sociopolítica en Chile pre y post golpe de estado. ¿Tenías al lector chileno en mente cuando escribías o no?

Allende: En la época en que escribí La casa de los espíritus y De amor y de sombra había una muchacha chilena que había leído todo lo que yo escribía y era un fan incondicional. Entonces yo tenía la sensación de que cualquier cosa que escribiera era para ella. En un sentido era responsabilidad hacia ella; quería que esa lectora utópica o 
potencial se sintiera a gusto y también participara conmigo en la búsqueda de algo. Hoy día no pienso en ella concretamente, pero siempre pienso en un puñadito de gente, a quienes yo les estoy contando, como quien dice, en el living de mi casa un cuento. Y ésa es la forma en que escribo, en tono familiar e íntimo. Si pensara en los millones de lectores y en las traducciones, estaría bloqueada, no podría escribir.

Álvarez: ¿A qué autores chilenos lees hoy día?

Allende: Me parece que la poesía chilena es muy buena. Me interesa lo que se publica en Chile. Sin embargo, en este momento estoy leyendo mucha más literatura norteamericana de mujeres, de escritoras negras, chicanas, japonesa-americanas, chinaamericanas, nativo-americanas. Creo que están escribiendo libros muy distintos a los que yo estaba acostumbrada, los de hombres blancos norteamericanos. Pasar de Norman Mailer a Toni Morrison .... ¡qué maravilla, qué refrescante!

Álvarez: Nuevamente tu atracción por los marginales. Porque éstas son escritoras que están intentando interpretar culturas y vidas que han sido relegadas por generaciones.

Allende: Siento que somos hermanas, en la misma búsqueda, en el mismo tono.

Álvarez: En este momento no eres exiliada sino que emigrante. ¿Qué es lo mejor y lo peor de vivir en Marin County, USA?

Allende: Lo mejor es el paisaje y una sensación de seguridad que no conocía. Nunca me había sentido tan segura. Aquí hay mucho menos crimen que en otras partes, puedes dejar tu auto abierto y no te lo roban, los niños pueden andar en la calle. Eso es tal vez lo mejor ... bueno, por supuesto haciendo la salvedad de que vivo con Willie. Podría vivir con él en cualquier parte. Lo peor de Marin County es el aislamiento. Uno está tan confortable aquí que llegas a pensar que esto es el mundo y te aíslas. Eso es un peligro grave para mí como ser humano y uno como escritora. ¡El mundo no es Marin County!

Álvarez: ¿Todavía tienes esa bolsita de tierra que te llevaste al salir al exilio?

Allende: Sí. Tengo eso y tengo otra con cinco monedas de un centavo que me dio mi mamá cuando yo era chica y tuvimos que separarnos. Empezó la guerra civil en el Líbano en el 58 y le pidieron a las familias de los diplomáticos que se fueran, entonces mi padrastro y mi mamá me mandaron de vuelta a la casa de mis abuelos en Chile. Al despedirnos mi mamá me dio una bolsita amarrada con unas monedas adentro y me dijo: "Toma, guárdalos, porque mientras tengas estos centavitos no te faltará para comer". Siempre la tengo conmigo, porque me parece tan simbólico eso de "no te faltará para comer". Y la verdad es que salvo una sola vez en la vida, y sólo por tres días, nunca me ha faltado para comer. 
